\title{
Angiotensin II attenuates renal cortical cyclooxygenase-2 expression
}

\author{
Hui-Fang Cheng, ,,2 Jun-Ling Wang, ${ }^{1,2}$ Ming-Zhi Zhang, ${ }^{1,3}$ Yoichi Miyazaki,, ${ }^{1,4}$ \\ Iekuni Ichikawa, ${ }^{1,4}$ James A. McKanna, ${ }^{1,3}$ and Raymond C. Harris ${ }^{1,2}$
}

\author{
${ }^{1}$ Vanderbilt George M. O'Brien Kidney and Urologic Diseases Center, \\ ${ }^{2}$ Division of Nephrology, Department of Medicine, \\ ${ }^{3}$ Department of Cell Biology, and \\ ${ }^{4}$ Department of Pediatrics, Vanderbilt University School of Medicine, Nashville, Tennessee 37232, USA \\ Address correspondence to: R.C. Harris, Division of Nephrology, S 3322, Medical Center North, \\ Vanderbilt University School of Medicine, Nashville, Tennessee 37232, USA. \\ Phone: (615) 343-0030; Fax: (615) 343-7156; E-mail: Ray.Harris@mcmail.vanderbilt.edu
}

Received for publication October 14, 1998, and accepted in revised form February 16, 1999.

\begin{abstract}
We have previously shown that in rat renal cortex, cyclooxygenase-2 (COX-2) expression is localized to cTALH cells in the region of the macula densa, and that dietary salt restriction increases COX-2 expression. Administration of the angiotensin converting inhibitor, captopril, further increased COX-2 mRNA and renal cortical COX-2 immunoreactivity, with the most pronounced expression in the macula densa. Administration of an AT1 receptor antagonist, losartan, also significantly increased cortical COX-2 mRNA expression and COX-2 immunoreactivity. Mutant mice homozygous for both Agtr1a and Agtr1b null mutations (Agtr1 $\mathrm{a}^{-/-}$,Agtr1 $\mathrm{b}^{-/}$) demonstrated large increases in immunoreactive COX-2 expression inthe cTALH/macula densa. To determine whether increased COX-2expression in response to ACE inhibition mediated increases in renin production, rats were treated with captopril for one week with or without the specific COX-2 inhibitor, SC58236. Plasma renin activity increased significantly in the captropril group, and this increase was significantly inhibited by simultaneous treatment with SC58236. Thus, these studies indicated that angiotensin II inhibitors augment upregulation of renal cortical COX2 in states of volume depletion, suggesting that negative feedback by the renin-angiotensin system modulates renal cortical COX-2 expression and that COX-2 is a mediator of increased renin production in response to inhibition of angiotension II production.
\end{abstract}

J. Clin. Invest. 103:953-961 (1999).

\section{Introduction}

Prostaglandins regulate vascular tone and salt and water homeostasis in the mammalian kidney and are involved in the mediation and/or modulation of hormonal action. Under basal conditions, inhibition of cyclooxygenase (COX) activity has little effect on renal function, but in situations of increased angiotensin II production, COX inhibition may have profound consequences for renal hemodynamics. Angiotensin II increases vasodilatory prostaglandin release in afferent arterioles and glomeruli, and angiotensin II vasoconstriction is significantly greater with inhibition of COX activity (1). It is also well documented that prostaglandins serve as regulators of the renin-angiotensin system $(2,3)$. COX inhibitors suppress plasma renin (4-7), and intrarenal infusion of arachidonic acid stimulates renin release (5). In addition, studies using an isolated perfused juxtaglomerular apparatus (JGA) preparation have confirmed that an intact COX pathway is necessary for the stimulation of renin release that is mediated by macula densa sensing of decreases in luminal $\mathrm{NaCl}$ (8). The conversion of arachidonic acid to prostaglandin $\mathrm{H}_{2}$ by prostaglandin $\mathrm{G}_{2} / \mathrm{H}_{2}$ synthase (COX) is a key enzymatic step in the regulation of prostanoid synthesis (9). In the kidney, constitutive prostaglandin $\mathrm{G}_{2} / \mathrm{H}_{2}$ synthase (COX-1) has been localized to mesangial cells, arteriolar endothelial cells, parietal epithelial cells of Bowman's capsule, and cortical and medullary collecting ducts (10). In addition to COX-1, certain cells express COX-2 in response to inflammatory or mitogenic stimuli (1-13). Using in situ hybridization and immunohistochemical localization, we have documented previously (14) that in normal adult rat kidney, COX-2 expression is localized to two cell types: occasional cTALH cells in the region of the macula densa and a subset of medullary interstitial cells near the papillary tip. After chronic salt depletion, COX-2 expression in the peri-macula densa region increases significantly $(14,15)$, although medullary interstitial cell expression decreases $(15,16)$. A potential role for COX-2 metabolites in regulation of renin release was suggested by a recent study by Harding et al. (17) demonstrating that administration of a selective COX-2 inhibitor prevented increases in renal renin mRNA levels in response to imposition of a low-sodium diet.

The mechanism by which COX-2 expression is regulated in the kidney has not been studied. Because of the evidence suggesting that angiotensin II can itself modulate the regulation of renin release (4), we examined whether angiotensin II might be a regulator of COX-2 expression in the cTALH/macula densa. Our findings suggest that angiotensin II inhibits cTALH expression of COX-2, suggesting that at least a component of the 
well-described feedback inhibition of angiotensin II on renin production may be mediated by regulation of COX-2 expression.

\section{Methods}

Materials. A rabbit polyclonal anti-COX-2 antibody was from Cayman Chemical (Ann Arbor, Michigan, USA). Goat anti-human uromucoid antibody was from ICN Biomedicals Inc. (Costa Mesa, California, USA). Anti-goat IgG (high and low) was from Vector Laboratories (Burlingame, California, USA). The COX-2 inhibitor, SC58236, was a gift from Searle Monsanto Co. ${ }^{32} \mathrm{P}-\mathrm{CTP}(3,000 \mathrm{Ci} / \mathrm{mmol})$, ECL (Enhanced Chemiluminescence Kit), and ECL Hyperfilm were from Amersham Life Sciences Inc. (Arlington, Heights, Illinois, USA). BCA Protein Assay Reagent Kit, Immunopure ABC Peroxidase Staining Kit, and biotin-labeled mouse anti-rabbit IgG (high and low) antibodies were from Pierce Chemical Co. (Rockford, Illinois, USA). ${ }^{125}$ I Ang I RIA was from Du Pont NEN Research Products (Boston, Massachusetts, USA). Losartan potassium was from Merck \& Co. (Whitehouse Station, New Jersey, USA), and PD123319 was from RBI-Sigma (Natick, Massachusetts, USA). Other reagents were purchased from Sigma Chemical Co. (St. Louis, Missouri, USA).

Animals. Male Sprague-Dawley rats (Harlan Bioproducts for Science Inc., Indianapolis, Indiana, USA), initially weighing 150-200 g, were given the angiotensin-converting enzyme (ACE) inhibitor captopril (100 $\mathrm{mg} / \mathrm{kg}$ body weight per day) (18) or an $\mathrm{AT}_{1} \mathrm{R}$ selective antagonist, losartan $(20 \mathrm{mg} / \mathrm{kg} /$ day $)$, in the drinking water for 7 days (19). A subset of animals were given a single intraperitoneal dose of furosemide $(1 \mathrm{mg} / \mathrm{kg})$ and then placed on rat chow deficient in sodium $(0.02-0.03 \%$ $\mathrm{Na}^{+}$) (ICN Radiochemicals Inc., Irvine, CA) for the same period. The $\mathrm{AT}_{2} \mathrm{R}$ antagonist PD123319 (30 mg/kg/day) (20) was administered by miniosmotic pump (Alza Pharmaceuticals, Mountain View, California, USA) for 7 days. The COX-2-specific inhibitor SC58236 $(10 \mathrm{mg} / \mathrm{kg} /$ day $)$ was administered by gastric gavage. Blood pressure was measured by the tail-cuff microphonic manometer method (21). Blood urea nitrogen (BUN), creatine (Cr), and sodium were measured by a Hitachi 704 chemical analyzer (Roche Dianostics, Corp., Indianapolis, Indiana, USA). In other studies, COX-2 immunoreactivity was determined in mutant mice homozygous for both Agtr1a and Agtr1b null mutation (Agtr1 $\mathrm{a}^{-/-}$; Agtr1 $\mathrm{b}^{-/}$) and age-matched C57BL/6 wild-type mice (22).

Primary culture of rabbit cTALH cells. cTALH cells were isolated from homogenates of rabbit renal cortex by immunodissection with anti-Tamm Horsfall antibody $(23,24)$. Briefly, the renal cortex was dissected, minced, and digested with $0.1 \%$ collagenase. After blocking with $10 \%$ BSA, the sieved homogenates were incubated with goat anti-human Tamm Horsfall antiserum $(50 \mathrm{mg} / \mathrm{ml})$ for $30 \mathrm{~min}$ on ice, followed by washing and addition to plastic Petri dishes coated with anti-goat IgG (8 $\mathrm{mg} / \mathrm{ml}$ ). Attached cells resistant to washing were dislodged and grown to confluence in DMEM/F12 with $10 \%$ FCS. Quiescent

Table 1

Effect of captopril treatment

\begin{tabular}{lcccc}
\hline & Control & Low salt & Captopril & $\begin{array}{c}\text { Low salt } \\
+ \text { captopril }\end{array}$ \\
Systolic BP(mmHg) & $124 \pm 8$ & $103 \pm 12$ & $105 \pm 8$ & $113 \pm 12$ \\
Serum $\mathrm{Cr}(\mathrm{mg} / \mathrm{dl})$ & $0.46 \pm 0.03$ & $0.54 \pm 0.05$ & $0.44 \pm 0.02$ & $0.48 \pm 0.05$ \\
Serum BUN $(\mathrm{mg} / \mathrm{dl})$ & $19.8 \pm 1.2$ & $45.4 \pm 11.3$ & $24.8 \pm 1.9$ & $38.4 \pm 10.0$ \\
Serum sodium $(\mathrm{mEq} / \mathrm{l})$ & $149.4 \pm 1.2$ & $144.4 \pm 2.3$ & $144.4 \pm 0.8$ & $142.8 \pm 2.1$ \\
Urine sodium $(\mathrm{mEq} / 24 \mathrm{~h})$ & $632.4 \pm 103.9$ & $45.6 \pm 7.1^{\mathrm{A}}$ & $2,368.8 \pm 98.5^{\mathrm{A}}$ & $116.2 \pm 23.3^{\mathrm{A}}$ \\
\hline
\end{tabular}

AP $<0.01$ compared with control.

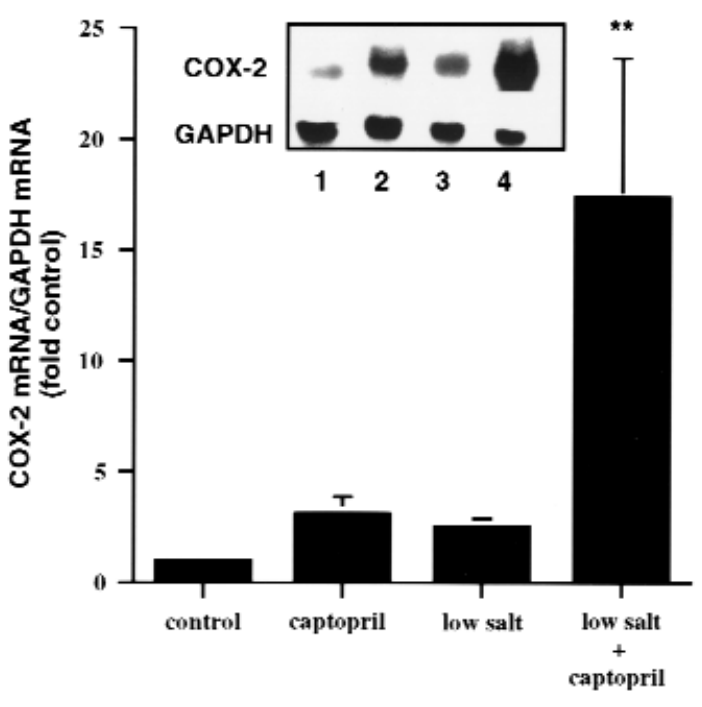

Figure 1

Captopril and/or low-salt diet increase renal cyclooxygenase-2 (COX-2) mRNA expression. Cortical COX-2 mRNA increased in animals fed either a sodium-deficient or normal diet and administered captopril. Administration of captopril to the rats fed a sodium-deficient diet increased COX2 mRNA expression significantly. Relative expression was normalized to glyceraldehyde phosphate dehydrogenase (GAPDH) expression $(n=5-9)$. Inset shows a representative experiment: 1 , control; 2 , captopril; 3 , low salt; 4 , captopril combined with low salt. ${ }^{*} P<0.01$, compared with control.

cTALH cells were incubated with or without angiotensin II $\left(10^{-9}-10^{-6} \mathrm{M}\right)$ for $24 \mathrm{~h}$ and with or without phorbol dibutyrate (PDB) $\left(10^{-7} \mathrm{M}\right)$, for $4 \mathrm{~h}$ before study.

RNA extraction and Northern blotting. Renal cortical RNA was extracted by the acid guanidinium thiocyanate-phenol chloroform method (25). RNA samples were electrophoresed in denatured agarose gel, transferred to nitrocellulose membranes, and hybridized with a $1.3-\mathrm{kb}{ }^{32} \mathrm{P}$-labeled cDNA KpnI/Xho1 fragment of 3' untranslated region of rat COX2 (14) or with ${ }^{32} \mathrm{P}$-labeled rat renin cDNA probe. The membranes were then stripped and rehybridized with glyceraldehyde phosphate dehydrogenase (GAPDH).

Immunoblotting. Renal cortices were homogenized in $30 \mathrm{mM}$ Tris-HCl (pH 8.0), $100 \mu \mathrm{M}$ PMSF (1:9 wt/vol). After a 10-min centrifugation at $10,000 \mathrm{~g}$, the supernatant was centrifuged for $60 \mathrm{~min}$ at $110,000 \mathrm{~g}$ to prepare microsomes, as described previously (26). Microsomal proteins were resuspended in SDS-sample buffer, heated to $100^{\circ} \mathrm{C}$ for $5 \mathrm{~min}$, separated on $8 \%$ SDS gels under reducing conditions, and transferred to Immobilon-P transfer membranes (Milipore Corp., Bedford, Massachusetts, USA). The blots were blocked overnight with $100 \mathrm{mM}$ Tris- $\mathrm{HCl}$ ( $\mathrm{pH} 7.4$ ) containing $5 \%$ nonfat dry milk, $3 \%$ albumin, and $0.5 \%$ Tween-20, followed by incubation for $16 \mathrm{~h}$ with polyclonal rabbit anti-murine COX-2 antiserum (Cayman Chemical) at $2.5 \mu \mathrm{g} / \mathrm{ml}$ dilution. The second reagent, biotinylated goat anti-rabbit antibody, was detected using avidin and biotinylated horseradish peroxidase (Pierce Chemical Co.) and exposed on film using ECL (Amersham Life Sciences Inc.).

Immunohistochemistry. Under deep anesthesia with Nembutal (Abbott Laboratories, North Chicago, Illinois, USA) (70 $\mathrm{mg} / \mathrm{kg}$ intraperitoneally), rats were exsanguinated with $50 \mathrm{ml} / 100 \mathrm{~g}$ heparinized 
saline $(0.9 \% \mathrm{NaCl}, 2 \mathrm{U} / \mathrm{ml}$ heparin, $0.02 \%$ sodium nitrite) through a transcardial aortic cannula and fixed with glutaraldehyde-periodate acid saline (GPAS), as described previously (27). GPAS contains final concentrations of $2.5 \%$ glutaraldehyde, $0.011 \mathrm{M}$ sodium metaperiodate, $0.04 \mathrm{M}$ sodium phosphate, $1 \%$ acetic acid, and $0.1 \mathrm{M} \mathrm{NaCl}$ and provides excellent preservation of tissue structure and COX-2 antigenicity. The fixed kidneys were dehydrated through a graded series of ethanols, embedded in paraffin, sectioned at $4-\mu \mathrm{m}$ thickness, and mounted on glass slides. COX-2 immunoreactivity was localized with COX-2 antiserum diluted to $2.5 \mathrm{ng} / \mathrm{ml}$. The first antibody was localized using Vectastain ABC-Elite (Vector Laboratories) with diaminobenzidine as the chromogen, followed by a light counterstain with toluidine blue.

Quantitative image analysis based on the distinctive density and color of COX-2 immunoreactivity and the number, size, and position of stained cells in video images from kidney sections was determined using BIOQUANT true-color windows system (R\&M Biometrics, Nashville, Tennessee, USA) equipped with digital stage encoders that allow high-magnification images to be mapped to global coordinates throughout the whole kidney. Sections from at least four different rats were analyzed for each time point (14).

Statistical analysis. All values are presented as mean \pm SEM. ANOVA and Bonferroni $t$ tests were used for statistical analysis, and differences were considered significant when $P<0.05$.

\section{Results}

Male Sprague-Dawley rats were fed either a control diet or a sodium-deficient diet for seven days, and a subset of these animals were also given the ACE inhibitor captopril in their drinking water. At the time of sacrifice, blood pressure was not significantly different among the groups; nor was serum creatinine (Table 1). BUN was significantly higher and urinary sodium excretion significantly lower than control in both groups of animals fed the sodium-deficient diet, although BUNs in the captopril-treated animals were not different from their respective controls. Captopril led to significantly greater natriuresis in animals fed a control diet and modestly increased urinary sodium excretion in the low-sodium group (Table 1).

Renal cortical RNA was extracted and hybridized with a ${ }^{32}$ P-labeled rat $3^{\prime}$ UTR COX-2 cDNA probe that does not cross-react with COX-1 (14). Blots were then stripped and reprobed with GAPDH cDNA for normalization. Consistent with our previous findings (14), cortical COX-2 mRNA increased in animals fed a sodiumdeficient diet $(240 \pm 50 \%$ of control); the relative increase in cortical COX-2 expression after one week on a sodium-deficient diet was less than what we had reported previously in animals on the same diet for more than three weeks (14). COX-2 mRNA expression was also increased in the rats fed a normal diet and administered captopril (310 $\pm 70 \%$ of control). Administration of captopril to the rats fed a sodium-deficient diet increased COX-2 mRNA expression $1,720 \pm 640 \%$ of control $(n=$ 5-9; $P<0.01$ ) (Figure 1, inset).

There was a similar trend for increases in renal cortical COX-2 immunoreactivity, as determined by immunoblotting, with a $150 \pm 30 \%$ increase in sodium-deficient animals, a $170 \pm 40 \%$ increase in the animals given captopril, and a $220 \pm 50 \%$ increase in animals given both captopril and a sodium-deficient $\operatorname{diet}(n=6-11 ; P<0.05)$ (Figure 2, inset).
COX-2 immunoreactivity was observed in the same general regions of the nephron as described previously (cTAL and macula densa); however, significant differences in localization were seen in animals receiving the ACE inhibitor. As reported previously $(14,27)$, in control male rats at seven weeks of age, individual epithelial cells or small clusters of cTAL stain intensely for COX-2; the stain fills the cytoplasm but the nucleus is unstained (not illustrated). After one week on the low-salt diet, increased numbers of COX2 -positive cells were observed in the vicinity of the macula densa (Figure $3 a$ ), but many macula densa cells were unstained (Figure $3 a$, arrow) and the predominant staining was seen in cTAL cells adjacent to the macula densa. In rats treated only with captopril, COX-2 immunoreactivity was localized to nearly all the cells of the macula densa but was not as intense as observed under other conditions (Figure $3 b$ ). Rats receiving both the low-salt diet and captopril expressed COX-2 in the macula densas of virtually every glomerulus (Figure 3c). Individual COX-2-positive cells were also present in the preglomerular segment of the CTAL (Figure $3 d$, arrowhead) but were absent from the postglomerular epithelium (initial segment of the distal convoluted tubule). Quantitation of the amount of cortical COX2 immunoreactivity indicated increases in both captopril and low-salt groups compared with control, with significantly greater COX-2 immunoreactivity with addition of captopril and low salt (ir-COX-2/cortical area: control: $52 \pm$ $8 \mu \mathrm{m}^{2} / \mathrm{mm}^{2}$; captopril: $84 \pm 15 \mu \mathrm{m}^{2} / \mathrm{mm}^{2}$; low salt: $129 \pm 39$ $\mu \mathrm{m}^{2} / \mathrm{mm}^{2}$; captopril + low salt: $419 \pm 109 \mu \mathrm{m}^{2} / \mathrm{mm}^{2}, n=4$; captopril + low salt vs. control: $P<0.01)$.

To investigate further the potential role of angiotensin II in cTALH/macula densa COX-2 expression, subtype-specific angiotensin II receptor antagonists were administered. Administration of the $\mathrm{AT}_{2}$ receptor antagonist, $\mathrm{PD} 123319$,

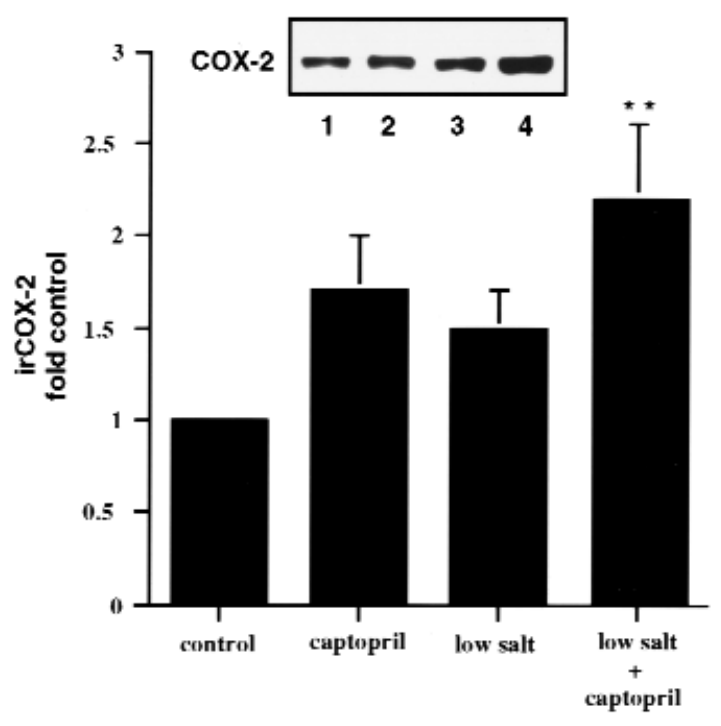

Figure 2

Captopril and/or low-salt diet increase renal cortical cyclooxygenase-2 (COX-2) immunoreactivity. Immunoreactive COX-2 (ir-COX-2) increased in animal fed either a sodium-deficient diet or normal diet and administered captopril. Administration of captopril to the rats fed a sodium-deficient diet increased ir-COX-2 expression significantly $(n=6-11)$. Inset shows a representative experiment: 1 , control; 2, captopril; 3 , low salt; 4 , captopril combined with low salt. ${ }^{*} P<0.01$, compared with control. 

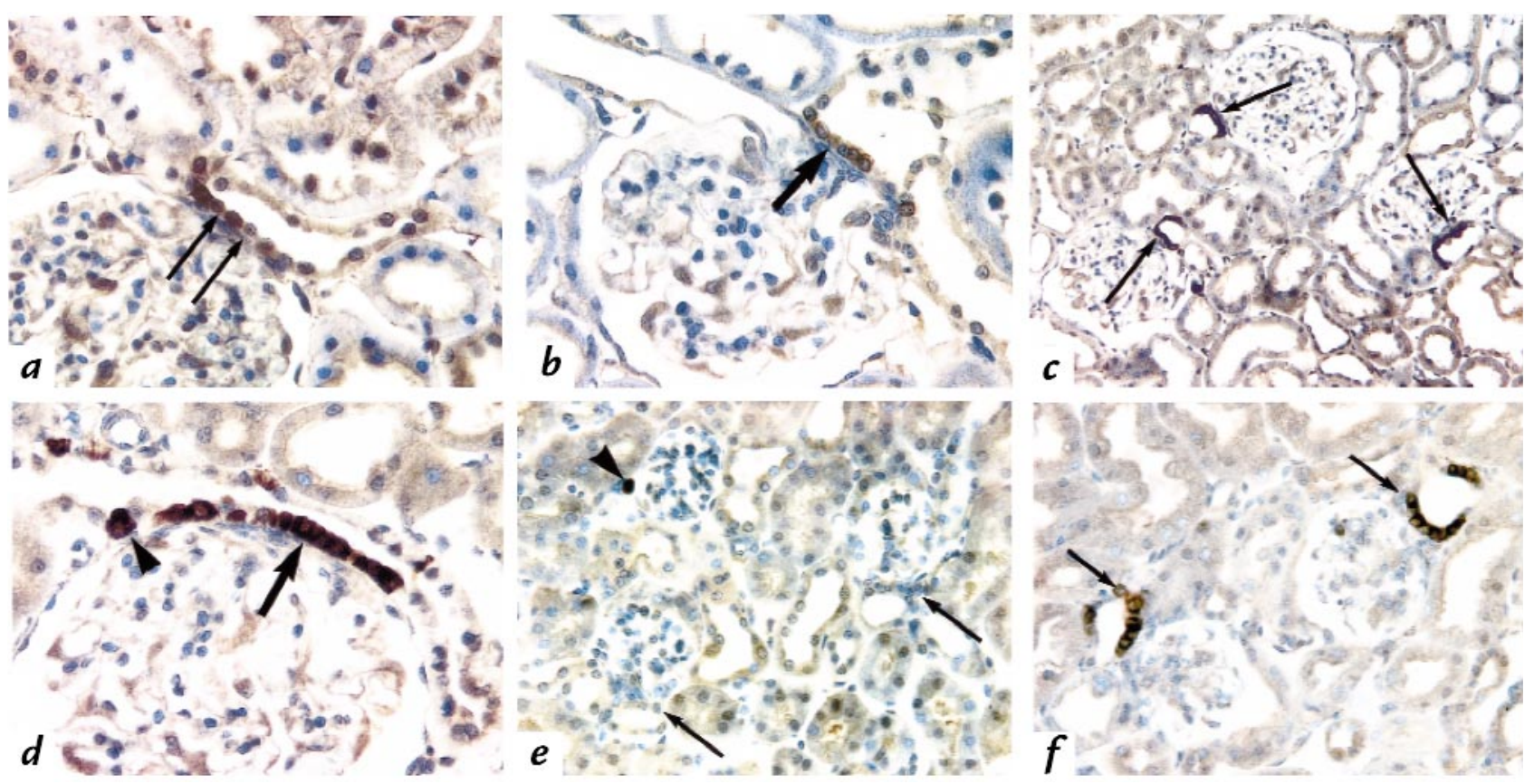

Figure 3

Localization of increased ir-COX-2 expression in captopril- and/or low salt-treated rats $(\boldsymbol{a}-\boldsymbol{d})$ and mutant mice homozygous for both Agtr1a and Agtr1b null mutation ( $\boldsymbol{e}$ and $\boldsymbol{f}$ ). (a) Low-salt diet. Many COX-2 cells are apparent in or near the macula densa, but numerous cells are unstained (arrows). (b) Captopril treatment. COX-2 protein is detected in many macula densa cells (arrow), but staining is less intense. ( $c$ and $d)$ Low-salt and captopril. Intense ir-COX-2 is apparent in macula densa of most glomeruli (arrows), as well as in isolated cTAL cells (arrowhead). (e) COX-2 immunoreactivity in C57BL/ 6 wild-type mice. Absence of COX-2 immunoreactivity in macula densa region (arrows) and ir-COX-2 in an interstitial macrophage (arrowhead). $(f)$ Intense ir-COX-2 macula densa/cTALH of (Agtr1 $\mathrm{a}^{-/-}$, Agtr1 $\left.\mathrm{b}^{-/-}\right)$mice (arrows). $a, b$, and $d: \times 450 ; c: \times 180 ; e$ and $f: \times 250$.

did not alter cortical COX-2 mRNA or immunoreactive protein levels in either control or sodium restricted rats (Figure $4 a$ ). In contrast, administration of the $\mathrm{AT}_{1}$ receptor antagonist losartan increased COX- 2 mRNA $(2.0 \pm 0.4$ of control, $n=5)$ and immunoreactive protein expression (1.5 \pm 0.3 of control, $n=6)$ in rats on control diet and further increased expression in salt-deficient animals (mRNA: 3.0 \pm 0.3 of control, $n=5, P<0.01$; ir-COX-2: $2.4 \pm 0.3, n=6, P$ $<0.01)$, similar to what was observed with ACE inhibition (Figure $4, b$ and $c$ ). The pattern of COX-2 immunoreactivity was also similar to that seen with captopril, with a predominant increase in macula densa ir-COX-2 expression (not shown). Losartan administration did not significantly alter systemic blood pressure compared with control animals (systolic blood pressure: losartan + control diet: 116 $\pm 6 \mathrm{mmHg}$; losartan + sodium-deficient diet: $113 \pm 4$ $\mathrm{mmHg}, n=5$ ).

To examine further the role of $\mathrm{AT}_{1}$ receptor in regulation of cTALH/macula densa COX-2 expression, COX-2 immunoreactivity was determined in mutant mice homozygous for both Agtr1a $\mathrm{a}^{-/}$and Agtr1b-/- and agematched C57BL/ 6 wild-type mice (22). Figure $3 e$ indicates that in wild-type adult mice, there was minimal, if any, COX-2 immunoreactivity in the macula densa region (Figure $3 e$, arrows). For comparison, COX-2 immunoreactivity could be detected in occasional interstitial macrophages (Figure 3e, arrowhead). In contrast, in Agtr1a $\mathrm{a}^{-/}$; Agtr1 $\mathrm{b}^{-/-}$mice, abundant COX-2 immunoreactivity was observed in the macula densa/cTALH region (Figure $3 f$ ).
To examine whether angiotensin II directly modulated CTALH COX-2 expression, primary cultures of rabbit cTALH were isolated by immunodissection with an anti-Tamm Horsfall antibody. In preliminary studies of these cells in culture, immunofluorescence studies indicated expression of Tamm Horsfall protein and COX-2. When grown to confluence and made quiescent for 24 hours by removal of serum, Northern and Western analysis indicated these cells expressed detectable basal levels of COX-2 immunoreactivity (Figure $5 a$ ). In quiescent cells, administration of angiotensin II did not alter basal levels of ir-COX-2 expression. However, when COX2 immunoreactivity expression was stimulated by phorbol dibutyrate (PDB) administration, preincubation for 24 hours with angiotensin II inhibited this phorbol ester-mediated induction of COX-2 expression (Figure $5 a)$. In other experiments, similar inhibition was observed when cTALH cells were preincubated with angiotensin II for 16 hours before administration of PDB. The inhibitory effect of angiotensin II was abrogated by preincubation with losartan, whereas PD123319 preincubation had no effect (Figure $5 b$ ).

To determine whether increased COX-2 expression mediated increases in renin production in response to ACE inhibition, rats were treated with captopril for one week with or without the specific COX-2 inhibitor SC58236. Plasma renin activity increased significantly in the captopril-treated group $(59.1 \pm 1.5$ vs. $4.3 \pm 0.6 \mathrm{ng}$ Ang I/h; $n=4, P<0.01)$. This increase was significantly blunted by simultaneous treatment with SC58236 (22.9 
$a$

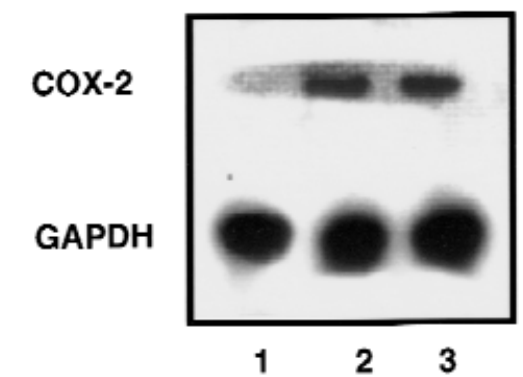

$b$

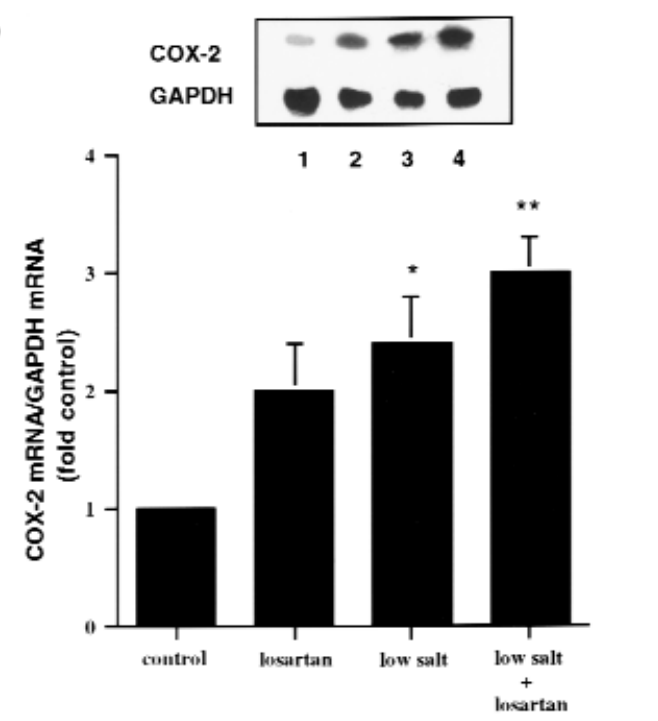

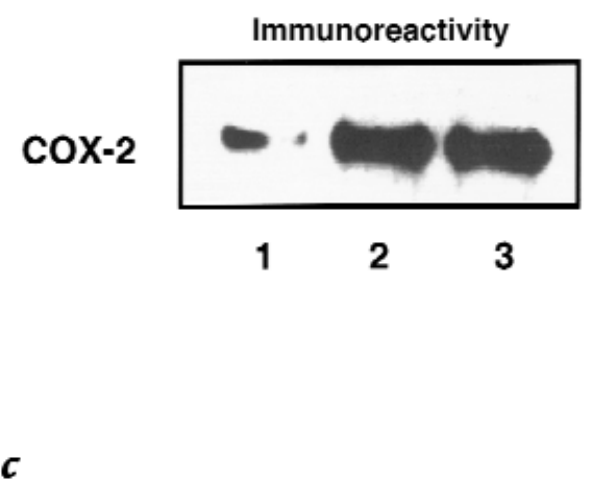

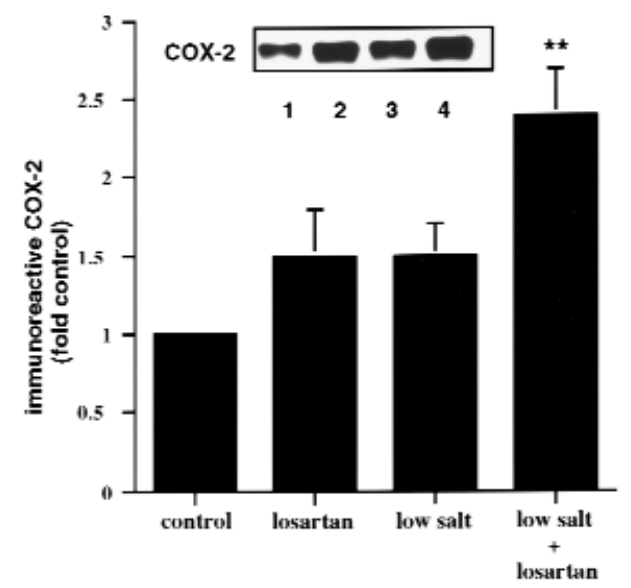

Figure 4

(a) Effect of an $\mathrm{AT}_{2} \mathrm{R}$ antagonist on renal cortical COX-2 expression. Administration of the AT 2 R antagonist PD123319 did not alter cortical COX-2 mRNA (left) or ir-COX-2 expression (right). Lane 1, control; lane 2, low salt; lane 3, low salt combined with PD123319. (b) Effect of an AT ${ }_{1}$ R antagonist on renal cortical COX-2 mRNA expression. Cortical COX-2 mRNA increased in animals fed either a sodium-deficient or normal diet and administered the $A T_{1} R$ antagonist losartan. Relative expression was normalized to GAPDH expression. Administration of losartan to the rats fed a sodiumdeficient diet increased COX-2 mRNA expression significantly $\left(n=5-9 ;{ }^{*} P<0.05\right.$ and ${ }^{*} P<0.01$ compared with control). Inset shows a representative experiment: 1, control; 2, losartan; 3 , low salt; 4, losartan combined with low salt. (c) Effect of an AT 1 R antagonist on renal cortical ir-COX-2 expression. Administration of losartan to rats fed a sodium deficient diet increased ir-COX-2 expression significantly $(n=6-11$; * $P<0.01$ compared with control). Inset shows a representative experiment: 1 , control; 2 , losartan; 3 , low salt; 4 , losartan combined with low salt.

$\pm 1.4 \mathrm{ng}$ Ang I/h; $n=4, P<0.01$ vs. captopril) (Figure 6a). Kidney renin activity also increased in the captopril group compared with control $(110.5 \pm 8.7$ vs. $10.2 \pm 1.5$ ng Ang I/h/mg protein; $n=4, P<0.01)$, which was also significantly inhibited by SC58236 (45.6 $\pm 8.2 \mathrm{ng}$ Ang $\mathrm{I} / \mathrm{h} / \mathrm{mg}$ protein; $n=4, P<0.01$ compared with captopril) (Figure 6b). Kidney renin mRNA expression normalized to GAPDH mRNA was also increased by captopril (1.95 \pm 0.37 -fold control; $n=4, P<0.05$ compared with control). SC58236 treatment prevented increases in renin mRNA expression $(1.0 \pm 0.15 ; n=4, P<0.05$ compared with captopril alone) (Figure $6 c$ ).

\section{Discussion}

The current studies were designed to investigate interactions of cTALH/macula densa expression of COX-2 with the renin-angiotensin system. Administration of either an ACE inhibitor or an $\mathrm{AT}_{1} \mathrm{R}$ antagonist to rats led to increases in cortical COX-2 expression in vivo, and murine double nullizygotes for the two $\mathrm{AT}_{1} \mathrm{R}$ subtypes also expressed abundant COX-2 immunoreactivity. In pri- mary cultures of cTALH cells, administration of angiotensin II inhibited phorbol ester-induced increases in COX-2 expression, suggesting a direct action of angiotensin II to downregulate cTALH/macula densa COX-2 expression. Furthermore, in rats treated with ACE inhibitors, elevations in plasma and kidney renin were significantly inhibited by simultaneous treatment with a selective COX-2 inhibitor, suggesting an important role for $\mathrm{CTALH} / \mathrm{macula}$ densa-derived prostanoids in the regulation of renin release in response to inhibition of angiotensin II production.

Prostacyclin generated by the afferent arteriole is thought to be involved in the mediation of renin release in response to alterations in intrarenal vascular tone (28), but studies have also indicated a role for prostanoids in macula densa-mediated renin release $(29,30)$. Ito et al. (31) found that isolated afferent arterioles without an associated macula densa increased renin release in response to prostacyclin but not prostaglandin $\mathrm{E}_{2}\left(\mathrm{PGE}_{2}\right)$. However, with an attached macula densa, $\mathrm{PGE}_{2}$ increased renin release, even in the presence of a 

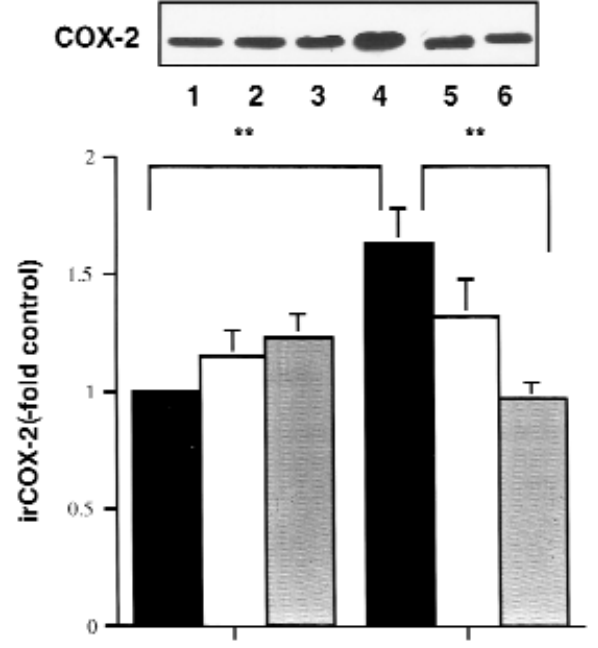

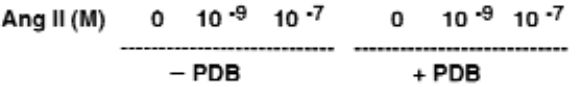

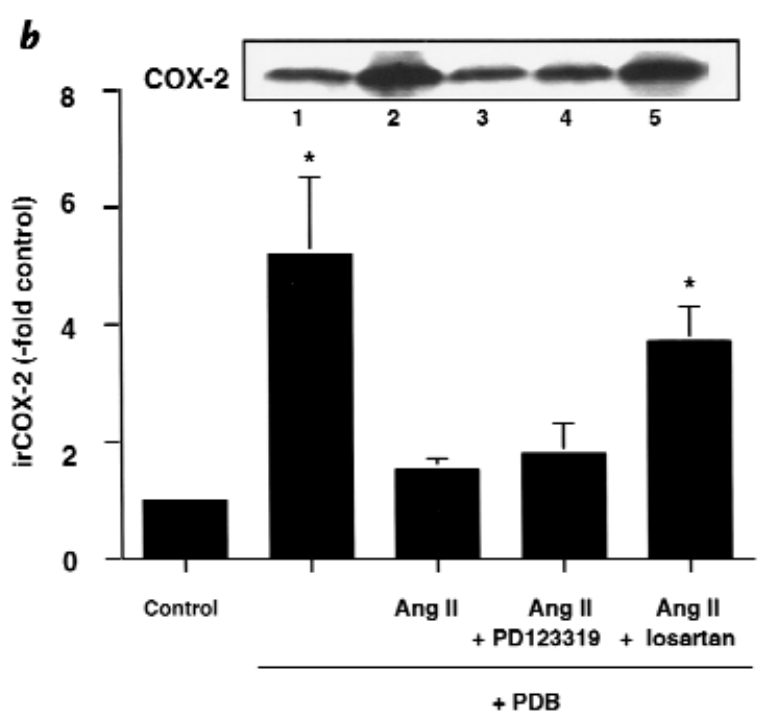

prostacyclin synthase inhibitor, and studies using an isolated perfused JGA preparation have confirmed that an intact COX pathway is necessary for stimulation of renin release mediated by macula densa sensing of decreases in luminal $\mathrm{NaCl}$ (8). Because previous studies (32) did not detect COX-1 immunoreactivity in cortical thick limb or macula densa, the origin of prostanoids mediating the macula densa response has been uncertain. The initial observation that renal cortical COX-2 expression in the rat is localized to the CTALH epithelia in the region of the macula densa raised the possibility that it might serve as a source for prostaglandins involved in regulation of renin release $(14,33)$. In support of this hypothesis, we found that imposition of a low-sodium diet or fluid restriction led to significant increases in cTALH/macula densa COX-2 expression, results that have subsequently been confirmed by other researchers $(15,16)$. There are coordinate increases in expression of COX-2 immunoreactivity and renin in the two kidney-one clip model of renovascular hypertension (34), and Harding et al. (17) have determined that adminis-

\section{Figure 5}

(a) Effect of angiotensin II incubation on ir-COX-2 expression in cultured CTAL cells. Quiescent primary cultured rabbit CTAL cells were incubated with Ang II for $24 \mathrm{~h}$ with or without coincubation of PDB for the final 4 h. PDB increased ir-COX-2 expression significantly $\left(n=6 ;{ }^{*} P<0.01\right)$, and $10^{-7} \mathrm{M}$ Ang $\mathrm{II}$ attenuated the PDB-stimulated ir-COX-2 expression ( $\left.n=3-6 ;{ }^{*} P<0.05\right)$. Inset shows a representative experiment: 1 , control;

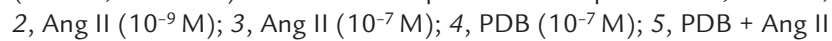
$\left(10^{-9} \mathrm{M}\right) ; 6, \mathrm{PDB}+\mathrm{Ang} \mathrm{II}\left(10^{-7} \mathrm{M}\right) .(\boldsymbol{b})$ Effect of $A T_{1} \mathrm{R}$ and $\mathrm{AT}_{2} \mathrm{R}$ antagonists on ir-COX-2 expression in cultured CTAL cells. Quiescent CTAL cells coincubated with Ang II and losartan or PD123319. Losartan, but not PD123319, prevented the Ang II-mediated inhibition of PDB-stimulated ir-COX-2 expression $\left(n=5 ;{ }^{*} P<0.05\right)$. Inset shows a representative experiment: 1, control; 2, PDB; 3, Ang II + PDB; 4, Ang II + PDB + PD123319; 5, Ang II + PDB + losartan. PDB, phorbol dibutyrate.

tration of NS398, a selective COX-2 antagonist, significantly inhibited increases in renin mRNA expression and renal renin content in response to a low-salt diet.

The mechanism by which COX-2 metabolites generated by the macula densa might stimulate renin production and release has not yet been determined. $\mathrm{PGE}_{2}$ is known to inhibit net chloride reabsorption in the (non-macula densa) cells of the thick ascending limb of Henle (35); therefore, locally produced prostanoids may function as autocoids to inhibit macula densa transport directly. Alternatively, prostanoids might affect signaling by the extracellular mesangial (Goormatigh) cells (36) or directly stimulate renin secretion by juxtaglomerular (jg) cells. In this regard, Jensen et al. (6) have determined that both $\mathrm{PGI}_{2}$ and $\mathrm{PGE}_{2}$ can stimulate increased renin mRNA expression and secretion in isolated jg cells, probably by increasing cAMP generation.

It has long been recognized that renal renin production is modulated by angiotensin II $(4,37)$. Increased renal tubule reabsorption, mediated directly by angiotensin II and indirectly by aldosterone, will reestablish intravascular volume homeostasis and thereby decrease the stimulus for renin release. In addition, angiotensin II directly inhibits renal renin production and release by a so-called short-loop feedback inhibition (37). Administration of either ACE inhibitors or $\mathrm{AT}_{1}$ receptor antagonists results in increases in both renin mRNA and immunoreactive protein in the kidney, in the absence of any detectable alteration in intravascular volume or renal hemodynamics $(4,38,39)$.

It has traditionally been assumed that angiotensin II inhibits renin production by a direct action on the juxtaglomerular cells $(40,41)$. However, a recent study by Matsusaka et al. (42) in chimeric mice carrying a regional null mutation of the angiotensin type $1 \mathrm{~A}\left(\mathrm{AT}_{1 \mathrm{a}}\right)$ receptor, the $\mathrm{AT}_{1}$ receptor subtype exclusively present in mouse jg cells, has questioned whether angiotensin II does act directly on juxtaglomerular cells. In these studies, the jga of $\mathrm{AT}_{1 \mathrm{a}}$ receptor homozygous mice were markedly enlarged, with intense expression of renin mRNA and protein. In the chimeric mice, the changes in the jga were proportional to the degree of chimerism, but the degree of jga hypertrophy/hyperplasia and the expression of renin mRNA and protein were not different in $\mathrm{AT}_{1 \mathrm{a}}$ receptor expressing and $\mathrm{AT}_{1 \mathrm{a}}$ receptor null $\mathrm{jg}$ cells. Therefore, the presence or absence of $\mathrm{AT}_{1}$ receptors 
on jg cells was not the determining factor of whether angiotensin II could regulate jga renin synthesis.

The results of the current study suggest an alternative or additional mechanism by which angiotensin II may inhibit renin release. If angiotensin II inhibits cTALH/macula densa COX-2 expression, it may limit the relative increases in COX-2 expression in response to volume depletion and, thus, the macula densa's ability to signal renin release. Given that similar effects were noted with both $\mathrm{ACE}$ inhibition and $\mathrm{AT}_{1}$ receptor antagonism, it is likely that $\mathrm{AT}_{1}$ receptors on the cTALH/macula densa mediate this angiotensin II-modulated COX2 expression. $\mathrm{AT}_{1}$ receptors have been identified in both mTALH and cTALH, as well as macula densa (43), although relatively few studies have examined the functional role of angiotensin II (44-46). However, preliminary studies (47) have indicated direct effects of angiotensin II to stimulate $\mathrm{Na}^{+} / \mathrm{H}^{+}$exchange in macula densa cells that were mediated by $\mathrm{AT}_{1}$ receptors, and studies by Mokuda et al. (48) in isolated perfused kidney have suggested that intrarenal angiotensin II may inhibit macula densa function. It is also of interest that in angiotensinogen knockout mice, nNOS expression in the macula densa is significantly increased (49).

It is well recognized that angiotensin II increases prostaglandin production acutely in a variety of renal and extrarenal cells, and prostaglandins serve to modulate or counteract the vasoconstrictive effects of angiotensin II on the renal and extrarenal vasculature (9). Acute stimulation of prostaglandin production by angiotensin II results from activation of phospholipase $\mathrm{A}_{2}$ and release of arachidonic acid, which is then further metabolized to prostanoid species by COX. In contrast, the present studies described a chronic effect of angiotensin II on COX-2 expression, although the mechanism of action of angiotensin II has not yet been determined.

Although phorbol ester-stimulated COX-2 expression in cultured cTALH cells was inhibited by pretreatment with angiotensin II, it was also of interest that these cells expressed basal levels of COX-2 immunoreactivity even in the absence of exogenous stimuli. In vivo, only a few scattered COX-2-positive cTALH cells are normally present in adult rat or rabbit kidney, but it is not clear whether there is only a subset of cTALH cells that can express COX-2 or whether all cTALH cells retain the capacity. We would favor the latter possibility because studies by us (27) and others (33) have indicated that in immature and young adult rats, there are significantly more COX-2-expressing cTALH cells than in older adult rats. Furthermore, an increased number of COX-2-positive cTALH cells is seen with low-salt diet (14) or hypercalcemia (50).

Although our in vitro studies indicated that angiotensin II can directly prevent stimulation of COX2 expression in cultured cTALH cells, it is possible that in vivo, additional components of the renin-angiotensin system may also regulate macula densa COX-2 expression. In this regard, deoxycorticosterone acetate (DOCA) administration decreased the increased macula densa COX-2 expression that is seen after adrenalectomy (Zhang, M.-Z., et al., unpublished results). Furthermore, we cannot completely rule out the possibility that the ACE inhibition- and $\mathrm{AT}_{1} \mathrm{R}$ antagonist-mediated increas- a

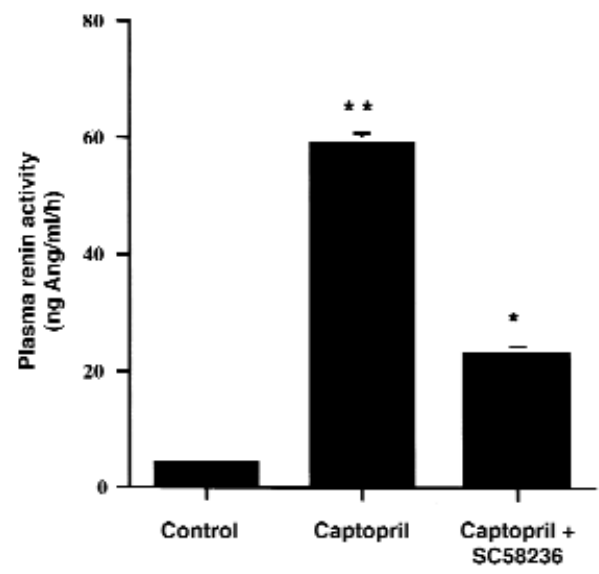

$b$
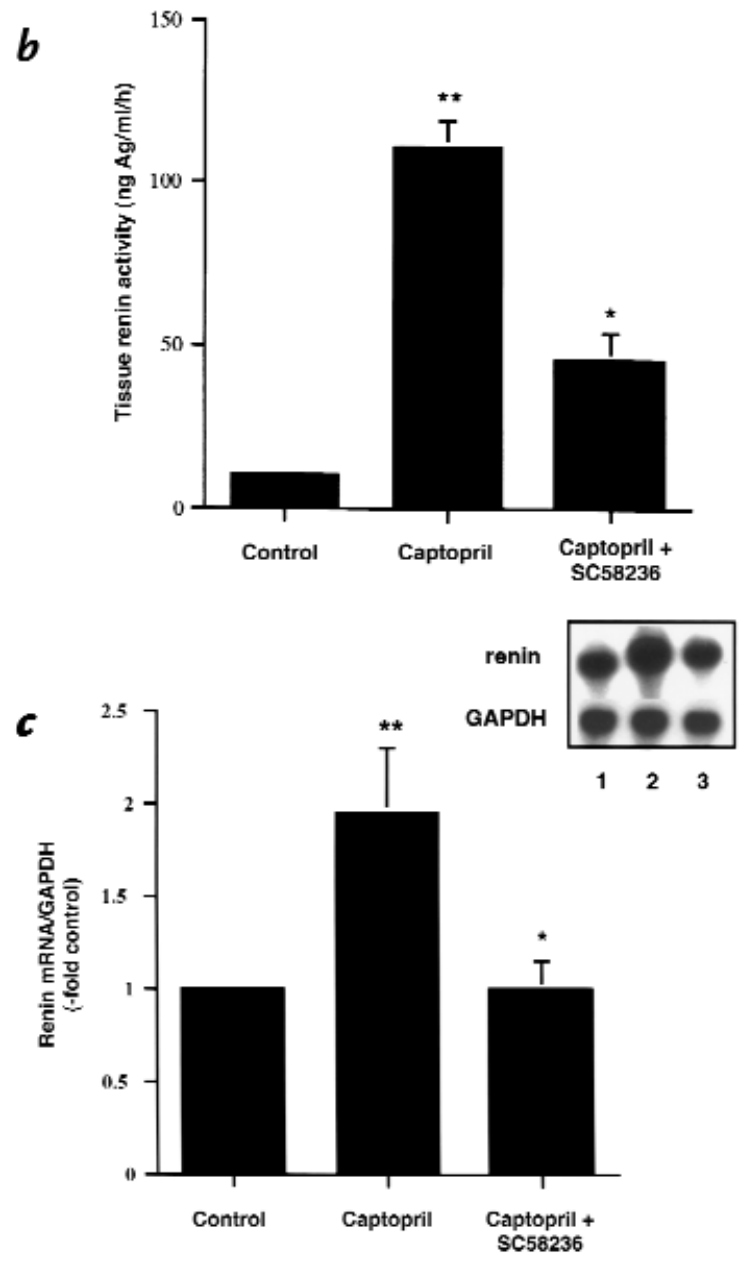

Figure 6

(a) The COX-2 inhibitor SC58236 reverses captopril-mediated increases in plasma renin. Plasma renin increased significantly in rats administered captopril ( $100 \mathrm{mg} / \mathrm{kg}$ body weight per day in drinking water) $\left(n=4 ;{ }^{*} P\right.$ $<0.01$ compared with control); captopril-induced increased plasma renin activity was significantly inhibited by SC58236 $(n=4 ; * P<0.01$ compared with captopril group). (b) SC58236 reverses captopril-induced increases in renal renin activity. Renal renin activity increased significantly in rats administered captopril $\left(n=4 ;{ }^{*} P<0.01\right)$, which was significantly inhibited by SC58236 ( $n=4 ;{ }^{*} P<0.05$ compared with captopril group). (c) SC58236 reverses captopril-induced increases in renal renin mRNA expression. Renal renin mRNA increased significantly in rats administered captopril $\left(n=4 ;{ }^{*} P<0.05\right)$, which was significantly inhibited by SC58236 ( $n$ $=4 ;{ }^{*} P<0.05$, compared with captopril group). Inset shows a representative experiment: 1 , control; 2, captopril; 3, captopril + SC58236. 
es in COX-2 expression in the in vivo studies were in part secondary to decreases in renal blood flow, with resultant sensing of effective volume depletion by the macula densa. However, we were unable to detect significant alterations in systemic blood pressure in either captopriltreated or losartan-treated animals compared with nontreated animals, nor were serum creatinines significantly different, indicating preservation of renal function. As expected, BUN was higher and urinary sodium excretion lower in the animals on a salt-deficient diet compared with the control diet; however, there was not a further significant increase in the captopril-treated low-salt animals, arguing against significantly greater volume depletion than their non-captopril-treated littermates. The lack of significant effects of ACE inhibitors or $\mathrm{AT}_{1} \mathrm{R}$ antagonists to decrease blood pressure in the sodiumdeficient group was presumably due to the short exposure to the diet. Finally, increases in cTALH/macula densa COX-2 expression could be noted in ACE inhibitor-treated animals fed a normal diet.

Mangat et al. (50) recently determined that increased COX-2 expression in the renal papilla in response to chronic hypercalcemia was significantly decreased by losartan. We did not examine COX-2 expression in the papilla in response to ACE inhibition or $\mathrm{AT}_{1} \mathrm{R}$ antagonism, but it is of interest that papillary COX-2 expression increases in response to a high-salt diet $(15,16)$, suggesting that different regulatory mechanisms are operative for papillary and CTALH/macula densa COX2 expression. It should be noted that Mangat et al. did not observe that losartan decreased the increases in cortical COX-2 expression seen in response to hypercalcemia. In fact, in their experiments, treatment with losartan for three days led to renal cortical COX-2 expression that was numerically, but not statistically, significantly greater than in the nontreated animals.

In summary, administration of either ACE inhibitors or $\mathrm{AT}_{1}$ receptor antagonists led to increased cTALH/macula densa COX-2 expression in rats on either control or salt-deficient diets, and angiotensin II decreased COX-2 expression in cultured cTALH cells. Furthermore, COX-2 selective inhibitors significantly inhibited increased renal renin production and release in response to ACE inhibitors. Therefore, these studies suggest that negative feedback by the renin-angiotensin system modulates renal cortical COX-2 expression and that COX-2 is a mediator of increased renin production in response to inhibition of angiotensin II production.

\section{Acknowledgments}

This work was supported by the Vanderbilt George O'Brien Kidney and Urologic Diseases Center (National Institutes of Health grant DK 39261), a grant from Searle Monsanto, and funds from the Department of Veterans Affairs.

1. Navar, L.G., et al. 1996. Paracrine regulation of the renal microcirculation. Physiol. Rev. 76:425-536.

2. Lorenz, J.N., Greenberg, S.G., and Briggs, J.P. 1993. The macula densa mechanism for control of renin secretion. Semin. Nephrol. 13:531-542.

3. Schnermann, J. 1998. Juxtaglomerular cell complex in the regulation of renal salt excretion. Am. J. Physiol. 274:R263-R279.

4. Hackenthal, E., Paul, M., Ganten, D., and Taugner, R. 1990. Morphology, physiology, and molecular biology of renin secretion. Physiol. Rev. 70:1067-1116.
5. Jackson, E.K., Oates, J.A., and Branch, R.A. 1981. Indomethacin decreases arterial blood pressure and plasma renin activity in rats with aortic ligation. Circ. Res. 49:180-185.

6. Jensen, B.L., Schmid, C., and Kurtz, A. 1996. Prostaglandins stimulate renin secretion and renin mRNA in mouse renal juxtaglomerular cells. Am. J. Physiol. 271:F659-F669.

7.Schricker, K., Hamann, M., and Kurtz, A. 1995. Nitric oxide and prostaglandins are involved in the macula densa control of the renin system. Am. J. Physiol. 269:F825-F830.

8. Greenberg, S.G., Lorenz, J.N., He, X.R., Schnermann, J.B., and Briggs, J.P. 1993. Effect of prostaglandin synthesis inhibition on macula densa-stimulated renin secretion. Am. J. Physiol. 265:F578-F583.

9. Needleman, P., Turk, J., Jakschik, B.A., Morrison, A.R., and Lefkowith, J.B. 1986. Arachidonic acid metabolism. Annu. Rev. Biochem. 55:69-102.

10. Smith, W.L., and Bell, T.G. 1978. Immunohistochemical localization of the prostaglandin-forming cyclooxygenase in renal cortex. Am. J. Physiol. 235:F451-F457.

11. Masferrer, J.L., et al. 1994. Selective inhibition of inducible cyclooxygenase 2 in vivo is antiinflammatory and nonulcerogenic. Proc. Natl. Acad. Sci. USA. 91:3228-3232.

12. O'Banion, M.K., Winn, V.D., and Young, D.A. 1992. cDNA cloning and functional activity of a glucocorticoid-regulated inflammatory cyclooxygenase. Proc. Natl. Acad. USA. 89:4888-4892.

13. Fletcher, B.S., Kujubu, D.A., Perrin, D.M. and Herschman, H.J.R. 1992. Structure of the mitogen-inducible TIS 10 gene and demonstration that the TIS 10 -encoded protein is a functional prostaglandin G/H synthase. J. Biol. Chem. 267:4338-4344.

14. Harris, R.C., et al. 1994. Cyclooxygenase-2 is associated with the macula densa of rat kidney and increases with salt restriction. J. Clin. Invest. 94:2504-2510.

15. Yang, T., et al. 1998. Regulation of cyclooxygenase expression in the kidney by dietary salt intake. Am. J. Physiol. 274:F481-489.

16. Jensen, B.L., and Kurtz, A. 1997. Differential regulation of renal cyclooxygenase mRNA by dietary salt intake. Kidney Int. 52:1242-1249.

17. Harding, P., et al. 1997. Cyclooxygenase- 2 mediates increased renal renin content induced by low-sodium diet. Hypertension. 29:297-302.

18. Morton, J.J., Beattie, E.C., and Macpherson, F. 1992. Angiotensin II receptor antagonist losartan has persistent effects on blood pressure in the young spontaneously hypertensive rat: lack of relation to vascular structure. J. Vasc. Res. 29:264-269.

19. Oddie, C.J., Dilley, R.J., Kanellakis, P., and Bobik, A. 1993. Chronic angiotensin II type 1 receptor antagonism in genetic hypertension: effects on vascular structure and reactivity. J. Hypertens. 11:717-724.

20. Levy, B.I., et al. 1996. Chronic blockade of AT2-subtype receptors prevents the effect of angiotensin II on the rat vascular structure. J. Clin. Invest. 98:418-425.

21. Iwai, N., and Inagami, T. 1992. Identification of a candidate gene responsible for the high blood pressure of spontaneously hypertensive rats. $J$. Hypertens. 10:1155-1157.

22. Tsuchida, S., et al. 1998. Murine double nullizygotes of the angiotensin type $1 \mathrm{~A}$ and $1 \mathrm{~B}$ receptor genes duplicate severe abnormal phenotypes of angiotensinogen nullizygotes. J. Clin. Invest. 101:755-760.

23. Allen, M.L., et al. 1988. Immunodissection of cortical and medullary thick ascending limb cells from rabbit kidney. Am. J. Physiol. 255:F704-F710.

24. Dai, L.J., and Quamme, G.A. 1991. Intracellular Mg2+ and magnesium depletion in isolated renal thick ascending limb cells. J. Clin. Invest. 88:1255-1264.

25. Chomczynski, P., and Sacchi, N. 1987. Single-step method of RNA isolation by acid guanidinium thiocyanate-phenol-chloroform extraction. Anal. Biochem. 162:156-159.

26. Wang, J.-L., Cheng, H.-F., Zhang, M.-Z., McKanna, J.A., and Harris, R.C. 1998. Selective increase of cyclooxygenase-2 expression in a model of renal ablation. Am. J. Physiol. 275:F613-F622..

27. Zhang, M.Z., et al. 1997. Cyclooxygenase-2 in rat nephron development. Am. J. Physiol. 273:F994-F1002.

28. Whorton, A., et al. 1977. Prostaglandins and renin release. I. Stimulation of renin release from rabbit renal cortical slices by $\mathrm{PGI}_{2}$. Prostaglandins. 14:1095-1104.

29. Francisco, L.J., Osborn, J.L., and DiBona, G.F. 1982. Prostaglandins in renin release during sodium deprivation. Am. J. Physiol. 243:261-268.

30. Linas, S.L. 1984. Role of prostaglandins in renin secretion in the isolated kidney. Am. J. Physiol. 246:F811-F818.

31. Ito, S., Carretero, O.A., Abe, K., Beierwaltes, W.H., and Yoshinaga, K. 1989. Effect of prostanoids on renin release from rabbit afferent arterioles with and without macula densa. Kidney Int 35:1138-1144.

32. Smith, W.L., and Rollins, T.E. 1982. Characteristics of rabbit anti-PGH synthase antibodies and use in immunocytochemistry. Methods Enzymol. 86:213-222.

33. Vio, C.P., Cespedes, C., Gallardo, P., and Masferrer, J.L. 1997. Renal identification of cyclooxygenase- 2 in a subset of thick ascending limb cells. Hypertension. 30:687-692 
34. Hartner, A., Goppelt-Struebe, M., and Hilgers, K.F. 1998. Coordinate expression of cyclooxygenase- 2 and renin in the rat kidney in renovascular hypertension. Hypertension. 31:201-205.

35. Stokes, J.B. 1979. Effect of prostaglandin E2 on chloride transport across the rabbit thick ascending limb of Henle. Selective inhibitions of the medullary portion. J. Clin. Invest. 64:495-502.

36. Okuda, T., Kojima, I., Ogata, E., and Kurokawa, K. 1989. Ambient $\mathrm{Cl}^{-}$ions modify mesangial cell contraction by modulating cell inositol trisphosphate and $\mathrm{Ca}^{2+}$ via enhanced prostaglandin E2. J. Clin. Invest. 84:1886-1872.

37. Shricker, K., Holmer, S., Kramer, B.K., Riegger, G.A., and Kurtz, A. 1997. The role of angiotensin II in the feedback control of renin gene expression. Pflugers Arch. 434:166-172.

38. Gomez, R.A., et al. 1990. Recruitment of renin gene-expressing cells in adult rat kidneys. Am. J. Physiol. 259:F660-F665.

39. Campbell, D.J., Lawrence, A.C., Towrie, A., Kladis, A., and Valentijn, A.J. 1991. Differential regulation of angiotensin peptide levels in plasma and kidney of the rat. Hypertension. 18:763-773.

40. Johns, D.W., Peach, M.J., Gomez, R.A., Inagami, T., and Carey, R.M. 1990. Angiotensin II regulates renin gene expression. Am. J. Physiol. 259:F882-F887.

41. Inagami, T., et al. 1992. Localization of components of the renin-angiotensin system within the kidney and sustained release of angiotensins from isolated and perfused kidney. Tohoku J. Exp. Med. 166:17-26.

42. Matsusaka, T., et al. 1996. Chimeric mice carrying 'regional' targeted deletion of the angiotensin type $1 \mathrm{~A}$ receptor gene. Evidence against the role for local angiotensin in the in vivo feedback regulation of renin syn- thesis in juxtaglomerular cells. J. Clin. Invest. 98:1867-1877.

43. Harrison-Bernard, L.M., et al. 1997. Immunohistochemical localization of ANG II AT1 receptor in adult rat kidney using a monoclonal antibody. Am. J. Physiol. 273:F170-F177.

44. Ferreri, N.R., Escalante, B.A., Zhao, Y., An, S.J., and McGiff, J.C. 1998. Angiotensin II induces TNF production by the thick ascending limb: functional implications. Am. J. Physiol. 274:F148-F155.

45. Lu, M., et al. 1996. Effect of angiotensin II on the apical K+ channel in the thick ascending limb of the rat kidney. J. Gen. Physiol. 108:537-547.

46. Wolf, G., et al. 1995. ANG II is a mitogen for a murine cell line isolated from medullary thick ascending limb of Henle's loop. Am. J. Physiol. 268:F940-F947.

47. Bell, P.D., and Peti-Peterdi, J. 1991. Angiotensin II stimulates macula densa basolateral sodium/hydrogen exchange via type I angiotensin II receptors. J. Am. Soc. Nephrol. 10(Suppl.11):S225-S229.

48. Mokuda, O., Sakamoto, Y., Ubukata, E., and Shimizu, N. 1996. Captopril increases renin release stimulated by furosemide and hypotension in isolated perfused guinea pig kidneys. Horm. Metab. Res. 28:227-229.

49. Kihara, M., et al. 1997. The neuronal isoform of constitutive nitric oxide synthase is up-regulated in the macula densa of angiotensinogen geneknockout mice. Lab. Invest. 76:285-294.

50. Mangat, H., Peterson, L.N., and Burns, K.D. 1997. Hypercalcemia stimulates expression of intrarenal phospholipase A2 and prostaglandin $\mathrm{H}$ synthase-2 in rats. Role of angiotensin II AT1 receptors. J. Clin. Invest. 100:1941-1950. 